\title{
Internship Reflection
}

\author{
By Abigail Hawkins
}

D r. Charles Graham, my doctoral advisor, once stated that what happens in conference hallways is often more valuable than what happens in the sessions. After attending AECT in Louisville as an ECT Intern, I could not agree more. The most powerful thing I learned as an intern was how to network at a conference. I met amazing people and formed relationships with individuals I never thought possible.

I would like to pass on networking strategies to other graduates who, like me, may have felt peripheral and out of place at academic conferences. My advice is simple: insert yourself into the scene. Here are some ways to do it: 1.Have a plan. Before the conference, identify individuals you would like to meet. Ideally, you would be familiar with their work and their ideas relevant to your research. Contact them in advance and ask if you could take them out for coffee or chat with them during a session break. If you are not sure whom to meet, ask your advisor. Have questions prepared to ask about their research and how it relates to your own.

2.Bring business cards. You are probably thinking, "but I'm just a graduate student." And? If you are teaching or a research assistant, ask your department secretary if you can get cards made with the university logo. Pass them out to the people you meet. Ask them for theirs. Write on the back of the card the person's research area or employment and one personal fact you can recall from the conversation. When you get home, invite them to join your LinkedIn network.
3. Linger after sessions. Researchers love to talk about their research. After attending a session, stick around and talk with those who are still buzzing. Listen. Ask questions. Share ideas. Exchange cards. Become a part of the larger conversation and your research community.

4. Shell out the money. Attend that pricey division luncheon. You'll sit at

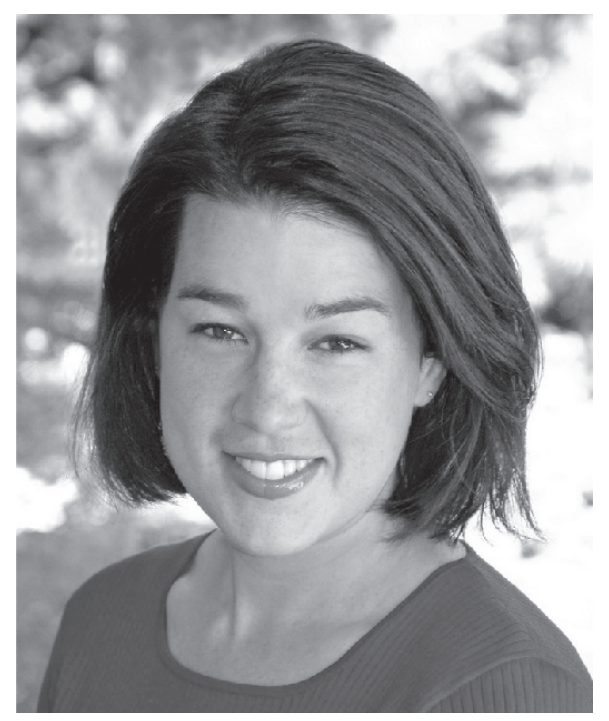

Abigail Hawkins

a table with eight other people interested in an area of research similar to your own. You will make friends, comment on how horrible the food is, and learn the inner workings of the division. Often there are service opportunities within the division. After the lunch, ask one of the division leaders if there is any volunteer division work you could participate in during the year.

5. Install the help of your faculty. I am so grateful to Dr. David Wiley and Dr. Rick West. After the second day of the conference, I pinged Dr. Wiley asking if he would introduce me to people the next morning. He was more than accommodating and introduced me to several individuals and potential employers. Similarly, Dr. West introduced me to several faculty members who were looking to hire.

6. Do the uncomfortable. I was horrified when Cindy York and Dr. Preston Parker said that as interns we were to invite ourselves to lunch with someone. I was of a mindset that one waits for an invitation. However, it is completely normal at a conference to ask if people have lunch plans and if you could join them (or if they would join you). So after lingering at a session and meeting people with similar research interests, be bold and ask if they have lunch plans. Make the first move. You'll be surprised by the outcome.

7. Pay it forward. Be inclusive by inviting other graduate students to join you for lunch. Introduce one another to people you know. My fellow interns Heather Leary, Eunjung Oh, and Nari Kim all introduced me to faculty from their departments. Similarly, I introduced them to faculty from my own. It was a simple, kind, and easy way to meet others through the use of my peer's network.

These were just a few networking strategies I learned as an intern at AECT. I hope they help other graduate students and that we can practice them together in the hallways at the Anaheim conference in October.

Abigail Hawkins is a doctoral student at Brigham Young University in Provo, Utah. 